\title{
Correction of Problematic Hypospadias with Dartos Fascia-Reinforced Flap and Slanted Incision of Fistula
}

\author{
Dong Sik Choi ${ }^{1}$, Jeong Woo Lee ${ }^{1}$, Jung Dug Yang ${ }^{1}$, Ho Yun Chung ${ }^{1}$, Byung Chae Cho', \\ Jin Suk Byun ${ }^{2}$, Kang Young Choi ${ }^{1}$ \\ ${ }^{1}$ Department of Plastic and Reconstructive Surgery, Graduate School of Medicine, Kyungpook National University, Daegu; ${ }^{2} B S$ Aesthetic \\ Clinic, Daegu, Korea
}

Background Hypospadias is the most common congenital malformation of the male urinary tract, wherein the urethral opening is located proximal to the normal site. Tubularized incisedplate urethroplasty reconstruction, and its efficacy, remains controversial due to the high recurrence rate. This study aimed to evaluate the results of dartos fascia-reinforced flap surgery in hypospadias patients with previous operative complications.

Methods Nine patients (mean age, 12 years) who had previous one- or two-stage repair with TIP urethroplasty and suffered from urethrocutaneous fistulas or fissures as complications, underwent dartos fascia-reinforced flap surgery in our clinic between January 2010 and December 2012. The mean postoperative follow-up period was 6 months.

Results Among the 9 patients, 7 had complete correction. In all the patients, the maximum uroflow angle was $>45^{\circ}$. No patient complained of an unnatural urinating position. The patients and parents gave very high satisfaction scores (4.7 points) with regard to the appearance of the outer genitalia.

Conclusion The dartos fascia-reinforced flap could be a useful and reliable option for complications of hypospadias repair or fissure with the prepuce preserved, given that histological aspects vary and that the possibility of recurrence in the glanular region is high.

Keywords Urethra / Fistula / Surgical flaps / Hypospadias
Correspondence: Kang Young Choi Department of Plastic and

Reconstructive Surgery, Graduate

School of Medicine, Kyungpook

National University, 130 Dongdeok-ro,

Jung-gu, Daegu 700-421, Korea

Tel: +82-53-420-5688

Fax: +82-53-425-3879

E-mail:kychoi@knu.ac.kr
No potential conflict of interest relevant to this article was reported.

\section{INTRODUCTION}

The etymology of hypospadias derives from a combination of the Greek words hypo (under) and spadon (orifice), referring to a split in the lower plane of the male urethra. Hypospadias is clinically characterized by the outer opening of the urethra, which should be located at the end of the glans, being ectopically located on the ventral side of the penis, resulting in the urethral opening being located inferior to the glans or toward the penile urethra. Hypospadias is morphologically defined as a congenital anomaly of the male urethra that originates from the incomplete fusion of the urethral fold of the ventral surface of the penis (Fig. 1) [1,2]. 


\section{Fig. 1. TIP and dartos fascia-reinforced flap surgery}

(A) Schematic diagram of a normal penile shaft. The black circular area is enlarged in Fig. 1B-F. (B) Tubularized incised-plate urethroplasty. (C) Dartos fascia-reinforced flap surgery. Tubulization of the urethral plate without incision. (D) Before coverage by the dartos and prepuce. (E) After advancement of the dartos and prepuce. (F) After coverage by the dartos and prepuce.

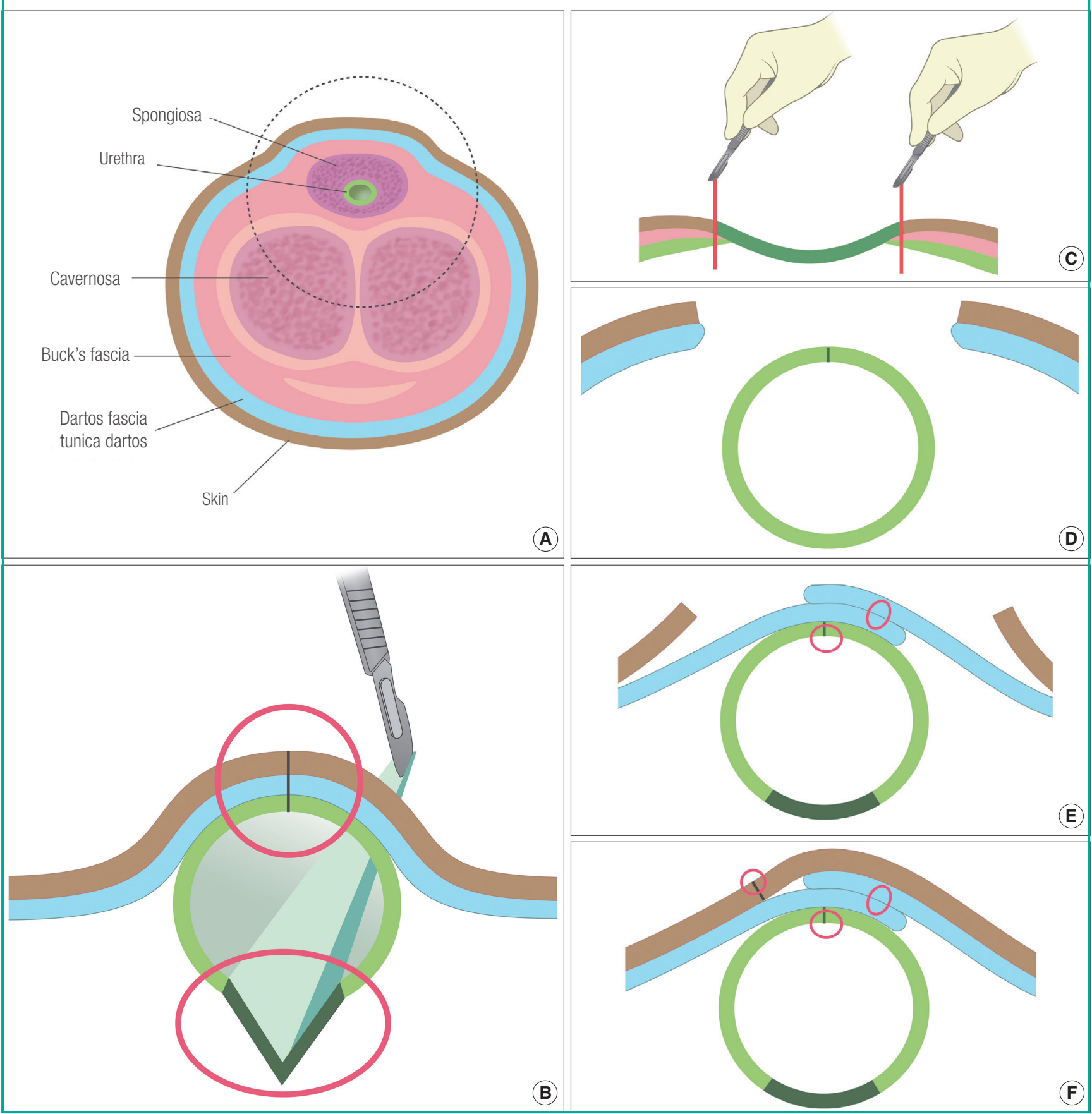

Although regional variations exist, hypospadias is considered to occur in approximately 1 of 300 male births [3-6]. It was reported that 4 of 5 boys developed fistulae after the tubularized incised plate procedure [7].

The most frequent location of the urethral orifice in hypospadias is the glans, followed by the penile shaft. Although rare, openings to the scrotum and perineum are associated with poor prognosis. Various classifications have been introduced, among which the most frequently used is the classification according to the location of the urethral orifice, that is, glanular, distal, and proximal [8].

Various surgical correction approaches for hypospadias are possible, depending on the location of the opening. However, surgical correction remains a difficult issue in pediatric urology. 
In particular, Snodgrass recently introduced the tubularized incised-plate (TIP) urethroplasty, which has been frequently used since $[1,2]$.

The goal of hypospadias surgery is the functional and cosmetic reconstruction of the urethra to make it suitable for coitus and allow urination in the standing position $[9,10]$. Typical complications of hypospadias surgery include urethral stricture, and urethrocutaneous fistula or fissure, with reported incidence rates ranging from $5 \%$ to $44 \%$ [10]. It is important to note that re-correction when complications occur is much more difficult than the initial correction owing to scar formation [6].

In this report, we describe the use of a dartos fascia-reinforced flap in 9 patients who suffered from complications after hypospadias surgery. We analyzed the clinical cases, in which functionally and cosmetically satisfactory results were obtained without notable complications. In addition, this study aimed to evaluate the efficacy of hypospadias surgery using the dartos fascia-reinforced flap technique.

\section{METHODS}

\section{Patients}

The patients who were admitted to our hospital between January 2010 and September 2012 with problematic recurrent hypospadias were included in this series. Among the patients, 3 had glanular, 4 had distal, and 2 had proximal hypospadias, according to the location of the meatus. The patients' data were retrospectively analyzed according to age, type of hypospadias, type of corrective surgery, and complications. Complications were classified either as a urethrocutaneous fistula (less than 5 $\mathrm{mm}$ ) or fissure (more than $5 \mathrm{~mm}$ ). After surgery, the patients were followed up for a minimum period of 6 months (Table 1 ).

\section{Surgical methods}

In patients who suffered from previous postoperative complications, a re-corrective surgery was performed by using the dartos fascia-reinforced flap technique. Correction was performed with tubulization of the urethral plate without incisions, using dartos and prepuce bilateral advancement flaps.

The surgery was begun by making a stay suture on the penis glans, followed by insertion of a 6- or 7-Fr silicone urethral catheter. For fissures of more than $5 \mathrm{~mm}$ or if the urethral opening was located in the middle or proximal region, the urethra had to be reconstructed lengthwise. First, depending on the size of the phallus, a 7- to 9-mm-wide tissue flap from the mucosal lining of the urethra was marked to cover the exposed urethral plate. At the chosen incision site, saline diluted in 1\% lidocaine was injected. Unlike in the TIP procedure, the midsection of the urethral plate was not incised, but the incision was made lengthwise on either side of the marked site (Fig. 1C). The flaps were carefully detached, taking precautions to maintain the blood supply of the flap (Fig. 1D). Then, the flaps on either side were turned

\section{Table 1. Patients' characteristics}

\begin{tabular}{|c|c|c|c|c|}
\hline Location (case) & Age (yr) & Initial diagnosis & Previous op history & Pre-reoperative problems \\
\hline \multicolumn{5}{|l|}{ Glanular } \\
\hline 1 & 16 & Glanular hypospadias & $\begin{array}{l}\text { Tubularized incised-plate } \\
\text { 2nd urethroplasty } \\
\text { 3rd urethroplasty }\end{array}$ & Wound disruption \\
\hline 2 & 17 & Glanular hypospadias & $\begin{array}{l}\text { Tubularized incised-plate } \\
\text { 2nd urethroplasty }\end{array}$ & Urethrocutaneous fistula \\
\hline 3 & 14 & Glanular hypospadias & Tubularized incised-plate & Urethrocutaneous fissure \\
\hline \multicolumn{5}{|l|}{ Distal } \\
\hline 4 & 15 & Penile hypospadias & Tubularized incised-plate & Urethrocutaneous fistula or fissure \\
\hline 5 & 12 & Penile hypospadias & $\begin{array}{c}\text { Release of web and cordectomy } \\
\text { Tubularized incised-plate } \\
\text { Urethroplasty } \\
\text { Urethroplasty }\end{array}$ & Urethrocutaneous fistula \\
\hline 6 & 11 & Penile hypospadias & $\begin{array}{l}\text { Tubularized incised-plate } \\
\text { Fistulectomy }\end{array}$ & Urethrocutaneous fistula and fissure \\
\hline 7 & 5 & Penile hypospadias & $\begin{array}{l}\text { Chordectomy } \\
\text { Tubularized incised-plate } \\
\text { Fistulectomy } \\
\text { Fistulectomy }\end{array}$ & Urethrocutaneous fistula and fissure \\
\hline \multicolumn{5}{|l|}{ Proximal } \\
\hline 8 & 11 & Penoscrotal hypospadias & Tubularized incised-plate & Hypospadias recurrence \\
\hline 9 & 4 & Perineal hypospadias & $\begin{array}{l}\text { Chordectomy } \\
\text { Tubularized incised-plate } \\
\text { Urethroplasty }\end{array}$ & Fistula \\
\hline
\end{tabular}


over to meet in the middle. Anastomosis was performed using 8-0 Vicryl sutures. The sutures were made in reverse, centered around the inner layer (Fig. 1E). Then, the dartos fascia on both sides was detached, and the flaps were laid so that they overlapped more than $5 \mathrm{~mm}$. Using 8-0 Vicryl sutures, the flaps were anastomosed away from the urethral plate suture line (Fig. 1F). Hence, with adequate blood flow, the dartos fascia was located at the end of the second layer. Thereafter, the skin was detached at different lengths from an area wider than the fistula anteroposteriorly and from left to right, taking precaution to maintain the blood flow. The suture line, where each layer of the urethral epidermis sutured together, did not overlay the approximation of the detached fascia. Using No. 11 and 15 scalpels, the margin edges were brought together, performing the detachment as tension-free as possible, and then sutured. Furthermore, the dorsal vessel and nerves that supplied the glans were not damaged (Fig. 2).

For simple fistulas, the urethral mucosa was detached, turned downward, and secured using 8-0 Vicryl sutures. The surrounding dartos fasciae were detached appropriately, made to overlap with each other, and sutured, ensuring that the suture line did not overlay the mucosa suture line. If Buck's fascia was present, it was detached as well. Then, the skin was undermined on both sides, advanced, and then anastomosed to the opposite side of the fascia suture using 8-0 or 6-0 Vicryl sutures.

\section{Postoperative evaluation}

The surgical site was examined for postoperative fistula or fis- sures. A profile photograph of urination was obtained to measure the angle of urinary flow at 6 months after operation. The cosmetic satisfaction and comfort level were determined via a satisfaction survey, using a 5-point scale (from 1, unsatisfied to 5 , very satisfied), to score each of the survey items.

\section{RESULTS}

In all of the 9 patients, no further complications were observed and the urinary stream was 45 degrees or higher, without further functional issues. In 2 patients, the meatus lengthened owing to a minor wound disruption of the glanular region, though without functional problems. The cosmetic satisfaction score of the patients who underwent dartos fascia-reinforced flap surgery and their parents were 4.7 , indicating high satisfaction (Figs. 2-4).

\section{DISCUSSION}

Diverse corrective surgical procedures for hypospadias have been developed. Urethroplasty procedures are selected according to the location of the urethral opening, associated penile deformation, ease in performing the procedure, incidence of complications, and the experience and preference of the surgeon. The TIP procedure, introduced by Snodgrass et al. [11] in 1994, uses a vertical incision of the urethral plate without additional flap surgery, thereby avoiding excess tension. Furthermore, since the ability of this procedure to allow for the most natural

\section{Fig. 2. Case of hypospadias (glanular fissure)}

A case of hypospadias (glanular fissure) in a 14-year-old boy. (A) Preoperative view. (B) Immediate postoperative view. (C) 6-month postoperative view.
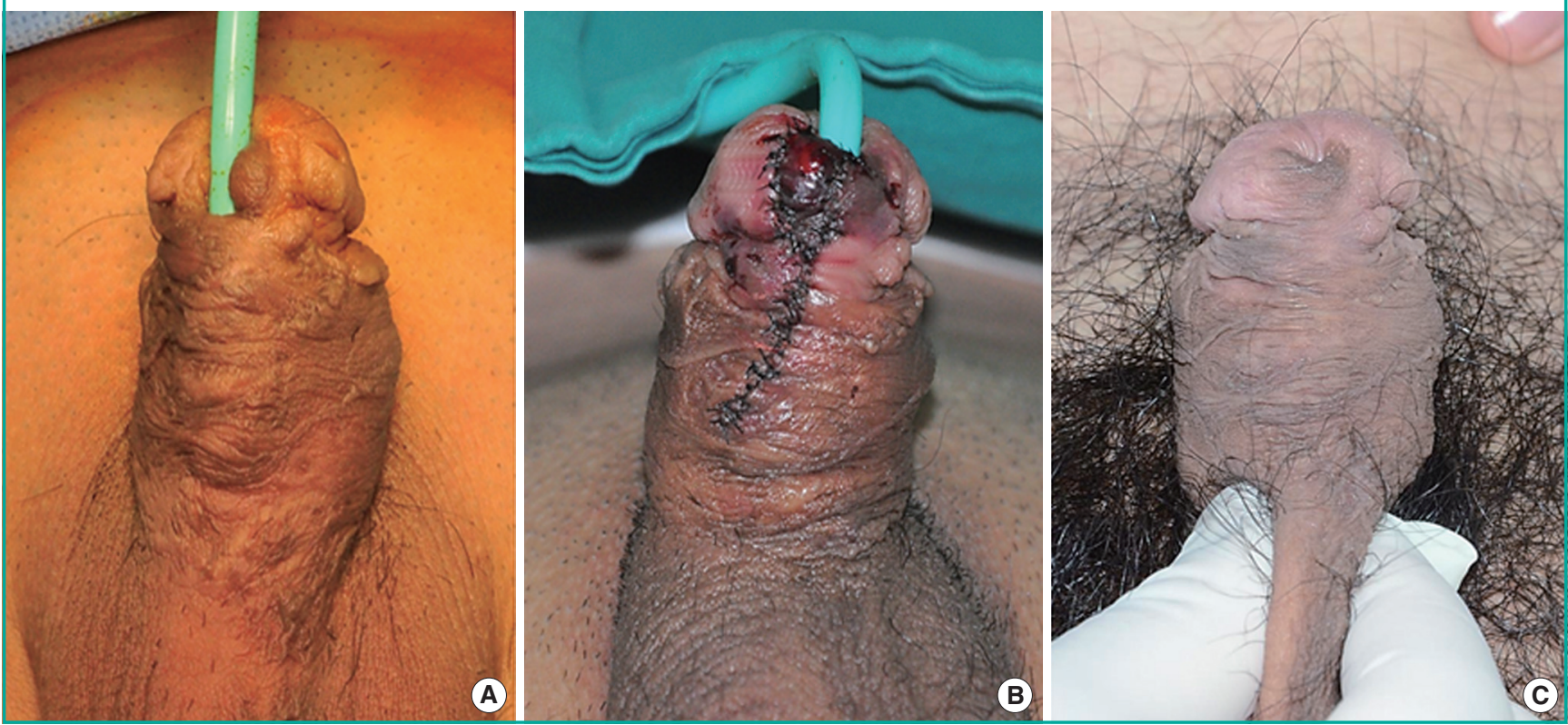


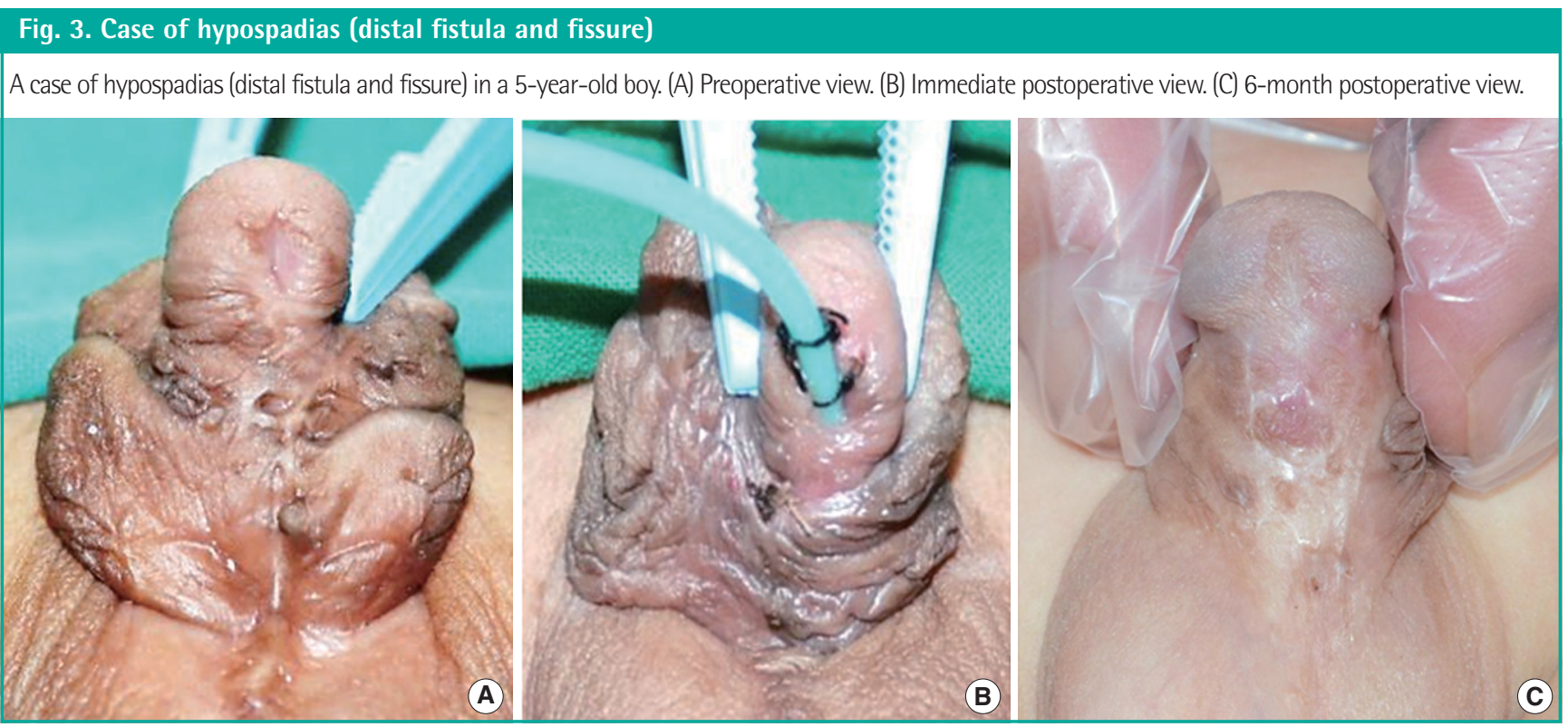

Fig. 4. Case of hypospadias (proximal fissure)

A case of hypospadias (proximal fissure) in an 11-year-old boy. (A) Preoperative view. (B) Immediate postoperative view. (C) 6-month postoperative view.
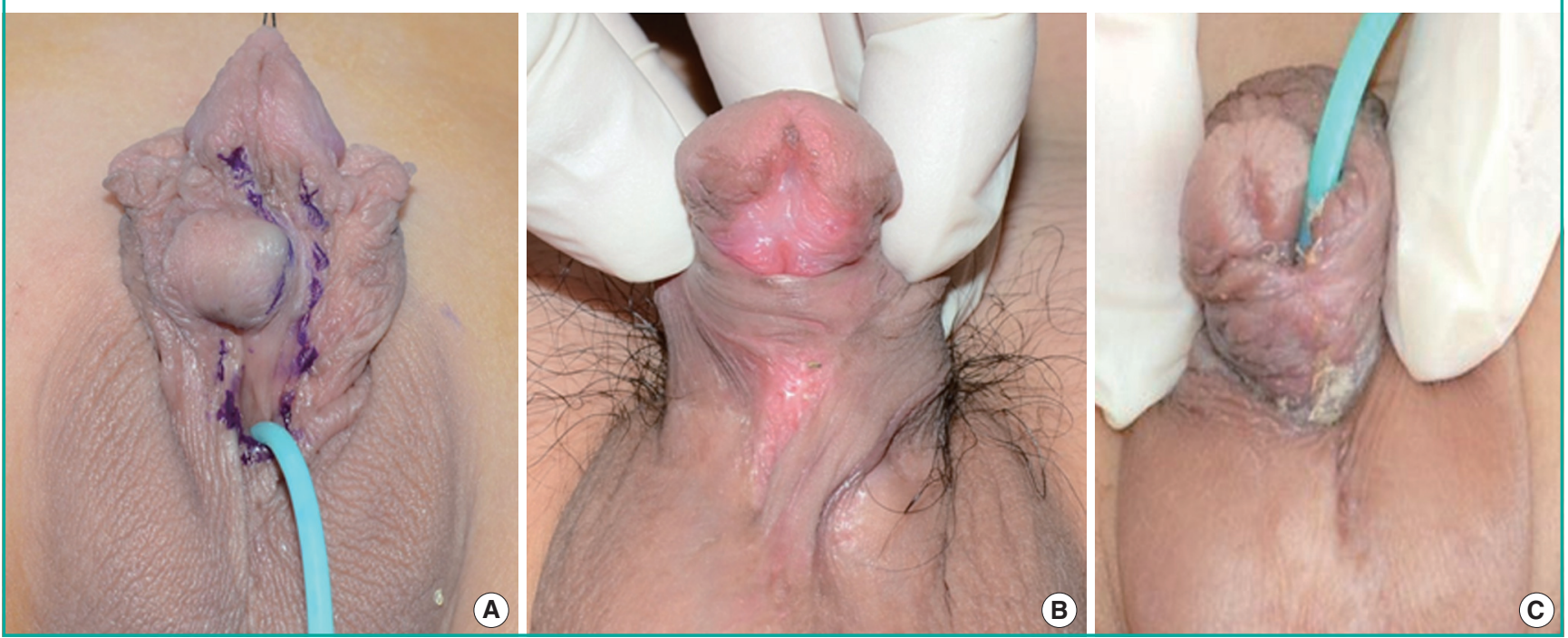

reconnection to the existing urethra without cicatrization of the urethra through re-epithelialization has been reported, it has become the most frequently used procedure. However, complications such as fistulas or fissures are still relatively frequently reported $[5,12]$.

The sources of complications include occlusion at the distal region of the new urethra, vascular distribution of the new urethral tissue, and postsurgical tissue infection. In addition, the location and shape of the original urethral opening, the surgical method used, and the experience of the surgeon are considered to play a role. For these various reasons, different forms of fistulas or fissures can occur anywhere in the junction of the new urethra or urethral plate. In particular, if hematoma or infection occurs at the site of the wound, blood flow becomes insufficient, which can lead to necrosis. During the tissue repair process, urethrocutaneous fistulas or fissures can form even more easily [5]. In cases of reoperation, the frequency of complications, including urethrocutaneous fistulas, is much higher than in the primary operation. The main causes are believed to be the cicatrization of the urinary plate, health of the tissue, and decrease in blood flow $[6,13]$.

In our study, continuity and vascularity were improved by using a $2.5 \times$ loupe to accurately verify the junction of the skin and urethral mucosa, detaching the layers carefully, locating the margin differently at each layer, and suturing layer by layer. The authors did not make a central incision of the urethral plate but 
Table 2. Glans and penile shaft layers

\begin{tabular}{|ll|}
\hline Glans & Penile shaft \\
\hline Epithelium & Epidermis \\
Lamina propria & Dermis \\
Corpus spongiosum & Dartos fascia \\
Tunica albuginea & Tunica albuginea \\
Corpus cavernosum & Corpus cavernosum \\
& Corpus spongiosum \\
\hline
\end{tabular}

a slanted incision of the fistula to prevent unnecessary tissue loss, and then the dartos and Buck's fasciae were lifted simultaneously to increase blood flow to the flap. Minimal undermining of the flap was performed. The flaps were sutured in a line away from the urethral plate suture so that in case of dehiscence of the urethral plate during wound healing, leakage could be prevented to facilitate faster wound healing. In case of fissures, as TIP urethroplasty had been performed previously, the urethral mucosa was already widened; therefore, an incision at the midsection of the urethral plate was not made to minimize tissue damage and maintain blood flow to the urethral plate. The treatment of fissures also followed the same main principles of creating different suture lines for each layer and overlapping the fascia layers.

Furthermore, in lifting and utilizing the dartos muscle flap, in the inversion of the urethral mucosa, and in suturing the urethra, a more intricate manipulation was used. Moreover, minimizing bleeding and tension, careful postoperative observation of the wound, appropriate dressing treatment, and prostaglandin agents have been used to minimize complications. However, a fistula or fissure of the glans area has been found to be difficult to correct, which is attributable to the dermis and fascia layer, which exist in the penile shafts of other patients of normal males but not in the glans as in our cases (Table 2).

Therefore, for patients with hypospadias, not performing circumcision and maximal preservation of the skin are advantageous for later purposes.

Early surgical correction of hypospadias has become more common with the advancement of pediatric surgical techniques and anesthesia. If hypospadias is not corrected early, it can lead to psychological problems; hence, it should be corrected before the patient enters school. The surgery is usually performed at 6 to 24 months after birth, before the child develops the concept of sex [8]. This is to minimize the anxiety of separation from the parent and the fear of surgery. If the initial surgery is not successful, reoperation is only possible after at least 6 months of follow-up. This period of 6 months is necessary not only to allow recovery from the inflammatory reaction and edema from the urethroplasty and recover the resilience and elasticity of the tissue but also to restore blood flow and repair the skin to accu- rately determine whether the skin around the fistula and fissure can be used for the reoperation $[10,14]$.

However, on the basis of the results of a univariate analysis, $\mathrm{Ha}$ and Lee [6] reported that the success of surgery was correlated with younger age at the time of reoperation and that if cicatrization occurred on the urethral plate, the rate of failure was higher. If the patient was older at the time of urethroplasty, the distance between the outer urethral opening and apex of the penis was longer, indicating a negative correlation with the success of reoperation. This is believed to be because of the increasing difficulty of restoring blood flow to the urethral tissue with age, leading to poorer health of the tissue [6]. Therefore, reoperation should be performed as soon as possible after the minimum follow-up period required after the first surgery.

In this study, we obtained satisfactory results from the reoperation using the dartos fascia-reinforced flap technique. However, our small patient sample size was not sufficient to assess the incidence of complications or functional restoration. We recommend that follow-up studies with a more diverse and larger patient sample be conducted to evaluate the efficacy of dartos fascia-reinforced flap surgery using the dartos and Buck's fasciae. Moreover, future follow-up studies on other surgical techniques are necessary to analyze and compare the utility of the techniques.

\section{REFERENCES}

1. Baskin LS, Ebbers MB. Hypospadias: anatomy, etiology, and technique.J Pediatr Surg 2006;41:463-72.

2. Paulozzi LJ, Erickson JD, Jackson RJ. Hypospadias trends in two US surveillance systems. Pediatrics 1997;100:831-4.

3. Gallentine ML, Morey AF, Thompson IM Jr. Hypospadias: a contemporary epidemiologic assessment. Urology 2001; 57:788-90.

4. Baran CN, Tiftikcioglu YO, Ozdemir R, et al. What is new in the treatment of hypospadias? Plast Reconstr Surg 2004; 114:743-52.

5. Barbagli G, De Angelis M, Palminteri E, et al. Failed hypospadias repair presenting in adults. Eur Urol 2006;49:88794.

6. Ha HK, Lee SD. Outcome and risk factors of tubularized incised plate urethroplasty in patients with reoperative hypospadias repairs. Korean J Urol 2009;50:67-71.

7. Abdel-Hamid Mohamid El-Hawy M. Minimal modifications could decrease fistula rate during tubularized incised plate procedure in distal hypospadias repair. J Pediatr Urol 2012 Nov 1 [Epub]. http://dx.doi.org/10.1016/j.jpurol. 2012.10.008. 
8. Korean Urological Association. Urology. 3rd ed. Seoul: Korea Publisher; 2001.

9. Yoo C, Moon K, Kim KS. The individualized surgical approach of penoscrotal transposition according to the anatomical position of the penis. Korean J Urol 2006;47:28792.

10. Kim MK, Kim YG. Hypospadias repair: recent concept and development in surgical techniques. Korean J Urol 2008; 49:1059-66.

11. Snodgrass WT, Bush N, Cost N. Tubularized incised plate hypospadias repair for distal hypospadias. J Pediatr Urol 2010;6:408-13.

12. Borer JG, Bauer SB, Peters CA, et al. Tubularized incised plate urethroplasty: expanded use in primary and repeat surgery for hypospadias. J Urol 2001;165:581-5.

13. Chon WH, Bang SI, Lee SD. Ten-year experience of adult hypospadias repairs at a single center. Korean J Urol 2008; 49:1144-8.

14. Manzoni G, Bracka A, Palminteri E, et al. Hypospadias surgery: when, what and by whom? BJU Int 2004;94:1188-95. 